\title{
Factors associated with hip joint rotation in former elite athletes
}

\author{
Jyrki A Kettunen, Urho M Kujala, Heli Räty, Tapio Videman, Seppo Sarna,
} Olli Impivaara, Seppo Koskinen

Unit for Sports and Exercise Medicine,

Institute of

Biomedicine,

University of Helsinki,

Helsinki, Finland

J A Kettunen

U M Kujala

H Räty

Faculty of

Rehabilitation

Medicine, University

of Alberta, Edmonton,

Canada

T Videman

Department of Public Health, University of

Helsinki, Helsinki,

Finland

S Sarna

Research and

Development Centre,

Social Insurance

Institution, Turku,

Finland

O Impivaara

Department of Diagnostic Radiology, Turku University

Hospital, University of

Turku, Turku, Finland

S Koskinen

Correspondence to J Kettunen, Unit for Sports and Exercise Medicine,

Mannerheimintie 17, FIN-00250 Helsinki, Finland.

Accepted for publication 2 September 1999

\begin{abstract}
Objectives-To study factors associated with passive hip rotation range of motion (ROM) in former elite male athletes.

Methods-Athletes were interviewed about hip pain, disability, lifetime occupational loading, and athletic training. The passive hip rotation was measured with a Myrin inclinometer in 117 former elite male long distance runners, soccer players, weight lifters, and shooters aged 45-68 years. Magnetic resonance imaging was used to detect hip osteoarthritis.

Results-There were no differences in passive hip rotation ROM between the four athlete groups nor between diverging lifetime loading patterns associated with occupational or athletic activities. Among the subjects without hip osteoarthritis, hip pain, and hip disability according to a stepwise linear regression analysis, the only factor that was associated with the passive hip rotation ROM was body mass index (BMI), explaining about $21 \%$ of its variation. Subjects with high BMI had lower passive hip rotation ROM than those with low BMI. There was no right-left difference in the mean passive hip rotation ROM in subjects either with or without hip osteoarthritis as determined by magnetic resonance imaging. Nevertheless, hip rotation ROM was clearly reduced in a few hips with severe caput deformity.

Conclusions-Long term loading appears to have no association with passive hip rotation ROM. On the other hand, the hip rotation value was lower in subjects with high BMI than in those with low BMI. A clear right-left difference in hip rotation was found only in those subjects who, according to our magnetic resonance imaging criteria, had severe hip osteoarthritis. These findings should be taken into account when hip rotation ROM is used in the clinical assessment of hip joints. (BrF Sports Med 2000;34:44-48)
\end{abstract}

Keywords: hip joint rotation; range of motion; osteoarthritis; athletic training; body mass index

Osteoarthritis is a common disorder characterised by pain and reduced range of motion (ROM) of the joints. Its prevalence and severity increase with age. ${ }^{1}$ Restricted rotation and flexion are established clinical indicators of hip osteoarthritis. $^{2}$

Hip inward and outward rotation ROM is larger in children and adolescents than adults. ${ }^{3}$
Roach and Miles ${ }^{4}$ concluded that, at least up to 74 years of age, any substantial loss of ROM should be considered abnormal. However, differences in methods and study populations make comparisons of results for ROM of the hip between studies rather difficult. ${ }^{5-8}$

In addition to age, ROM of the hip may be affected by a number of other factors including physical loading, ${ }^{9}$ activities of daily life, ${ }^{10}$ and anthropometric factors, such as body mass index (BMI).

Mechanical stress in farmers is known to increase their risk of developing osteoarthritis, ${ }^{11} 12$ Sporting activity has been shown to increase the risk of developing hip osteoarthritis. ${ }^{13}$ This increase is clear for sports involving traumatic loading such as soccer ${ }^{15}{ }^{16}$ but not so clear for sports such as running. ${ }^{17}$

Hip rotation measurement is a clinical manoeuvre performed when diagnosing hip osteoarthritis, but there are few data on factors other than osteoarthritis that change hip rotation ROM. The main aim of this study was to investigate the association between sports involving different ranges of hip rotation and loading and hip rotation ROM. A further aim was to study the associations between hip rotation ROM and other factors, such as age, hip osteoarthritis, reported hip pain or hip disability, work related physical activity, muscle tightness, and anthropometry, which, like athletic activity, may change the ROM of the hip.

We enrolled in this study former top level athletes consisting of long distance runners (medium range flexion-extension and long term repetitive loading), soccer players (wider range of hip motion, including rotation, and high risk of impact loads on hip joint), weight lifters (extreme range of flexion and high peak loads on hip joint), and shooters. Shooters represent athletes who generally take only light to moderate physical exercise.

\section{Methods}

In our study former male long distance runners, soccer players, weight lifters, and shooters participated in a structured two hour interview, clinical examinations, functional measurements, and a hip magnetic resonance imaging (MRI) examination.

SUBJECTS

We identified male athletes who had represented Finland between the years 1920 and 1965 at least once in the Olympic games, World or European championships, or international competitions (athletic contests be- 
Table 1 Characteristics of participants

\begin{tabular}{|c|c|c|c|c|}
\hline & $\begin{array}{l}\text { Long distance } \\
\text { runners }(n=28)\end{array}$ & $\begin{array}{l}\text { Soccer players } \\
(n=31)\end{array}$ & $\begin{array}{l}\text { Weight lifters } \\
(n=29)\end{array}$ & $\begin{array}{l}\text { Shooters } \\
(n=29)\end{array}$ \\
\hline \multicolumn{5}{|l|}{ Age (years) } \\
\hline Mean (SD) & $59.7(4.7)$ & $56.5(5.7)$ & $59.3(5.3)$ & $61.0(4.3)$ \\
\hline Range & $51-67$ & $45-67$ & $46-66$ & $50-68$ \\
\hline \multicolumn{5}{|l|}{ Height $(\mathrm{cm})$} \\
\hline Mean (SD) & $173.0(4.8)$ & $176.9(5.4)$ & $167.0(6.6)$ & $175.2(6.6)$ \\
\hline Range & $162.0-183.0$ & $165.0-187.0$ & $154.0-183.0$ & $164.0-188.0$ \\
\hline \multicolumn{5}{|l|}{ Weight $(\mathrm{kg})$} \\
\hline Mean (SD) & $75.7(9.7)$ & $84.2(12.1)$ & $80.7(13.8)$ & $81.9(8.4)$ \\
\hline Range & $60.0-108.0$ & $68.0-123.0$ & $57.0-111.0$ & $71.0-99.0$ \\
\hline \multicolumn{5}{|c|}{ Body mass index $\left(\mathrm{kg} / \mathrm{m}^{2}\right)$} \\
\hline Mean (SD) & $25.3(2.8)$ & $26.9(3.4)$ & $28.8(3.6)$ & $26.7(2.5)$ \\
\hline Range & $20.9-34.9$ & $22.0-38.8$ & $22.5-38.4$ & $22.9-30.8$ \\
\hline \multicolumn{5}{|c|}{ Hip osteoarthritis ${ }^{\star}$} \\
\hline No $(\%)$ & $3(12)$ & $3(12)$ & $4(20)$ & $6(24)$ \\
\hline \multicolumn{5}{|l|}{ Hip pain } \\
\hline \multirow{2}{*}{\multicolumn{5}{|c|}{ Hip disability }} \\
\hline & & & & \\
\hline No $(\%)$ & $2(7)$ & $1(3)$ & $1(3)$ & $1(3)$ \\
\hline \multicolumn{5}{|c|}{ Lifetime endurance training (hours) } \\
\hline Median & 8980 & 1530 & 1520 & 2480 \\
\hline Range & $1300-18752$ & 0-9936 & $0-8483$ & $0-8536$ \\
\hline \multicolumn{5}{|c|}{ Lifetime team sport training (hours) } \\
\hline Median & 0 & 8240 & 1150 & 140 \\
\hline Range & $0-3072$ & $3864-18514$ & $0-4888$ & $0-5500$ \\
\hline \multicolumn{5}{|c|}{ Lifetime power training (hours) } \\
\hline Median & 0 & 0 & 9460 & 0 \\
\hline Range & $0-1280$ & $0-1600$ & $284-16752$ & $0-1092$ \\
\hline \multicolumn{5}{|c|}{ Years in heavy work } \\
\hline Mean (SD) & $12.3(15.4)$ & $1.7(7.2)$ & $9.7(12.6)$ & $3.2(8.3)$ \\
\hline Range & $0.0-47.0$ & $0.0-40.0$ & $0.0-43.0$ & $0.0-38.0$ \\
\hline \multicolumn{5}{|c|}{ Hypermobility index } \\
\hline Mean (SD) & $0.7(0.9)$ & $1.0(1.3)$ & $0.8(0.8)$ & $0.9(1.2)$ \\
\hline Range & $0.0-5.0$ & $0.0-5.0$ & $0.0-2.0$ & $0.0-4.0$ \\
\hline \multicolumn{5}{|c|}{ Straight leg raising } \\
\hline Mean (SD) & $85.5(14.0)$ & $84.7(10.5)$ & $88.7(10.3)$ & $80.4(9.6)$ \\
\hline Range & $63.5-119.0$ & $60.0-110.0$ & $71.0-114.0$ & $56.0-92.5$ \\
\hline
\end{tabular}

${ }^{\star}$ Long distance runners, $\mathrm{n}=25$; soccer players, $\mathrm{n}=25$; weight lifters, $\mathrm{n}=20$ (19 cases documented by magnetic resonance imaging and one hip prosthesis); shooters, $n=25$.

tween two or more countries). ${ }^{18}$ In 1985 , a questionnaire eliciting information on health and lifestyle was mailed to all surviving athletes. The responders included 38 long distance runners, 89 soccer players, 40 weight lifters, and 35 shooters, who in 1992 were alive and $45-68$ years old. All the shooters $(n=35)$ and runners $(\mathrm{n}=38)$, as well as a sample of soccer players $(n=37)$ and weight lifters $(n=$ 37) comparable in age and occupation with the other groups (a total of 147 subjects), were invited to take part. Of these, $117(80 \%)$ agreed to participate: 28 long distance runners, 31 soccer players, 29 weight lifters, and 29 shooters. A postal questionnaire was mailed to those who declined to participate, and 19 $(63 \%)$ of them responded. The most common reason for non-participation was lack of time.

The interview, clinical examinations, and MRI readings were carried out independently by different investigators who were blinded to the results obtained by the others.

The study was reviewed and approved by the ethics committee of the research centre of the Social Insurance Institution (Turku, Finland).

INTERVIEW

The subjects were interviewed by one of the authors (HR) about hip pain, disability, lifetime occupational loading, and lifetime regular participation hours in different types of athletic training (endurance, team, power). The methods have been described in detail previously. ${ }^{19}{ }^{20}$ Table 1 shows the main characteristics and background factors in the four groups of athletes. Occurrence of hip pain dur- ing the past year was investigated separately for each hip. Those who reported hip pain in either hip at least once a month were classified as having monthly hip pain. Disability was scored as yes/no on a scale of 0 to 7 depending on whether the subjects reported pain or disability (a) during nocturnal bedrest, (b) for more than five minutes in the morning after getting out of bed, (c) while sitting for 30 minutes, $(d)$ during full support by the legs, (e) while walking more than $1 \mathrm{~km},(f)$ while going up or down stairs, and $(g)$ while squatting or bending forward. The sum of positive responses was calculated, and subjects scoring at least three points for either hip were considered to have a hip disability (yes).

\section{CLINICAL EXAMINATIONS AND FUNCTIONAL}

\section{MEASUREMENTS}

The clinical examinations and quantitative measurements were performed by the first author (JK). Each subject's weight $(\mathrm{kg})$ and height $(\mathrm{m})$ were measured and the BMI calculated. Subjects were placed in the supine position for the measurement of passive flexion and inward and outward rotation of the hip joint. Hip flexion was measured with the knee flexed using a two armed standard goniometer. As a standard goniometer is difficult to adapt for measurement of hip rotation, the latter was measured with the knee flexed with a Myrin inclinometer, which is based on a compass method. The total (inward and outward combined) rotation was used to avoid misclassification of inward and outward rotation. A correlation between radiological changes in the spine and inclinometer ROM measurement results has been reported..$^{21}$ Moreover, Viitanen and co-workers ${ }^{21}$ concluded that the reliability of ROM measurements as conducted in this study was good. Hip extension was measured, using a standard goniometer, with the subject lying prone with the knee extended. All hip ROM measurements were made following the recommendations of the handbook of the American Academy of Orthopedic Surgeons. ${ }^{5}$

Hamstring tightness was measured using passive straight leg raising, with the inclinometer placed just above the patella of the leg to be tested. The examiner placed his leg on the other leg to stabilise it, and raised the leg to be tested slowly and evenly, avoiding abduction and rotation and keeping the knee fully extended until tightness or pain restricted the movement. The mean of readings from the two legs was used in the calculations.

Systemic hypermobility was assessed using the Carter and Wilkinson score ${ }^{22}$ modified by Beighton and co-workers. ${ }^{23}$ The test included passive dorsiflexion of the little fingers beyond $90^{\circ}$, passive apposition of thumbs to the flexor aspect of the forearm, hyperextension of elbows beyond $10^{\circ}$, hyperextension of the knee beyond $10^{\circ}$, and flexion of the trunk with the knees in extension so that the palms of the hands rested on the floor.

MAGNETIC RESONANCE IMAGING

MRI was performed using a $1.5 \mathrm{~T}$ device (Magnetom; Siemens AG, Erlangen, Ger- 
Table 2 Passive range of motion (ROM) of the hip joint in the four groups of athletes. (calculated from mean values of measurements made on the right and left lower extremity)

\begin{tabular}{|c|c|c|c|c|c|}
\hline & $\begin{array}{l}\text { Long distance } \\
\text { runners }(n=28)\end{array}$ & $\begin{array}{l}\text { Soccer players } \\
(n=31)\end{array}$ & $\begin{array}{l}\text { Weight lifters } \\
(n=29)\end{array}$ & $\begin{array}{l}\text { Shooters } \\
(n=29)\end{array}$ & $p$ Value \\
\hline \multicolumn{6}{|l|}{ Extension $\left({ }^{\circ}\right)$} \\
\hline Mean (SD) & $18.0(5.5)$ & $17.1(6.0)$ & $15.8(6.5)$ & $19.0(5.0)$ & \multirow[t]{2}{*}{0.17} \\
\hline Range & $0.0-25.0$ & $0.0-28.5$ & $0.0-24.0$ & $12.0-30.5$ & \\
\hline \multicolumn{6}{|l|}{ Flexion $\left({ }^{\circ}\right)$} \\
\hline Mean (SD) & $139.7(14.1)$ & $140.6(10.3)$ & $139.4(11.0)$ & $140.4(5.7)$ & \multirow[t]{2}{*}{0.97} \\
\hline Range & $72.0-150.0$ & $95.0-152.5$ & $95.0-154.0$ & $126.5-150.0$ & \\
\hline \multicolumn{6}{|c|}{ Outward rotation $\left(^{\circ}\right)$} \\
\hline Mean (SD) & $35.6(8.4)$ & $36.9(7.2)$ & $36.6(5.1)$ & $37.8(4.9)$ & \multirow[t]{2}{*}{0.66} \\
\hline Range & $2.5-50.0$ & $20.0-47.5$ & $25.0-45.0$ & $25.0-47.5$ & \\
\hline \multicolumn{6}{|c|}{ Inward rotation $\left({ }^{\circ}\right)$} \\
\hline Mean (SD) & $18.9(5.9)$ & $19.4(4.7)$ & $20.3(4.5)$ & $19.3(7.4)$ & \multirow[t]{2}{*}{0.83} \\
\hline Range & $0.0-29.5$ & $8.5-29.0$ & $12.0-30.0$ & $9.0-40.0$ & \\
\hline
\end{tabular}

many) with a body coil. The subjects were supine during the MRI examinations. As they had a subsequent MRI examination of the lumbar spine, ${ }^{24}$ a three dimensional FISP (fast imaging with steady precession) sequence, which gives good visualisation of the articular cartilage in a relatively short time, was chosen. Axial slices of both hips were produced. The imaging parameters were as follows: repetition time 30 milliseconds; echo time 10 milliseconds; flip angle $40^{\circ} ; 256 \times 256$ matrix; field of view $36 \mathrm{~cm} ; 2 \mathrm{~mm}$ slice thickness with no interslice gap; total imaging time 8 minutes 14 seconds.

The MR images were analysed for narrowing of joint space, cysts, and deformation of head of femur. Joint space narrowing (cartilage signal) was graded from six slices representing the weight bearing area as follows: $0=$ normal; $1=$ decrease in one to three of the studied slices; $2=$ decrease in four to six of the studied slices; $3=$ clearly obliterated at least in one slice (no cartilage signal); 9 = cannot be evaluated. Cysts and deformation of the head of femur were graded as $0=$ no, $1=$ yes and $9=$ cannot be evaluated.

An athlete was considered to have hip osteoarthritis, if he had obliterated hip joint space (grade 3) or osteoarthritic deformation of the head of femur or cyst formation in the head of femur. In addition, one subject had undergone total hip replacement because of osteoarthritis and was therefore classified as osteoarthritic.

A total of 94 subjects were examined (25 long distance runners, 25 soccer players, 19 weight lifters, and 25 shooters). Fourteen were excluded because of foreign bodies or metallic implants, seven because of technical difficulties, one because of claustrophobia, and one because of having excessively broad shoulders.

STATISTICAL ANALYSIS

The statistical analyses were carried out using BMDP statistical software. One way analysis of variance and the mean hip inward or outward rotation, extension and flexion ROM value of right and left leg were used to compare group means. Analysis of variance was used to compare hip rotation right-left differences among subjects with unilateral hip osteoarthritis and those without such a finding. The mean total (inward and outward combined) rotation value of osteoarthritic hip joints and the mean value of the right and left total hip rotation in subjects without osteoarthritis was calculated to compare rotation differences among these two groups.

We used multiple linear regression analysis for associations between the passive hip rotation ROM and different factors. The mean value of the right and left hip rotation (inward and outward combined) was used in these analyses.

\section{Results}

Table 2 shows the mean values and ranges of the passive ROM of the hip (rotation, flexion, extension) for the four athlete groups. No statistically significant group differences were found between the groups, nor between the right and left lower extremities in the total material. The mean (SD) right-left difference in rotation was $6.9(10.2)^{\circ}$ in those with unilateral hip osteoarthritis $(n=14)$ and $4.2(4.6)^{\circ}$ in those $(\mathrm{n}=78)$ without this finding $(\mathrm{p}=0.10)$. Nevertheless, in four severe cases of caput deformity, the right-left rotation difference exceeded $10^{\circ}$. The mean (SD) total hip rotation was $54.9(12.7)^{\circ}$ in those hip joints with osteoarthritis and $56.8(9.1)^{\circ}$ in those without $(\mathrm{p}=0.51)$.

In total, $25 \%(4 / 16)$ of the subjects with hip osteoarthritis had monthly hip pain, whereas monthly hip pain was reported by $13 \%(10 / 79)$ of those without hip osteoarthritis $(p=0.20)$. Hip disability, on the other hand, was reported by $13 \%(2 / 16)$ of the subjects with hip osteoarthritis and by $3 \%(2 / 79)$ of those without $(\mathrm{p}=$ $0.07)$.

The average hip rotation ROM was significantly $(p<0.0001)$ smaller in subjects with hip pain $\left(43.3(15.3)^{\circ}, \mathrm{n}=14\right.$ ) than in those who had not experienced this $\left(58.4(7.9)^{\circ}, \mathrm{n}=81\right)$. Similarly, those with hip disability had significantly $(\mathrm{p}=0.0003)$ smaller mean rotations (37.9 $\left.(25.3)^{\circ}, \mathrm{n}=4\right)$ than those not reporting this $\left(57.0(9.1)^{\circ}, \mathrm{n}=91\right)$.

\section{MULTIVARIATE ANALYSIS}

Associations between hip rotation ROM and different covariates were studied in those who had undergone MRI ( $\mathrm{n}=94$, the subject with bilateral endoprothesis excluded). The calculations were based on the mean combined rotation of measurements made on the right and left hips. BMI, years in heavy work, lifetime participation hours in different types of athletic training, age, hypermobility index, athlete group, hip osteoarthritis, monthly hip pain, hip disability, and straight leg raising were entered into the model.

The only factors that were significantly associated with the hip rotation $\mathrm{ROM}$ were BMI $(20 \%)$ and monthly hip pain (9\%), explaining about $29 \%$ of its variation. The mean hip rotation was $61.1^{\circ}$ in those with BMI 24 or less (n $=20), 55.5^{\circ}$ in those with BMI between 24.1 and $28(\mathrm{n}=52)$, and $53.3^{\circ}$ if $\mathrm{BMI}$ was 28.1 or more $(n=22)(p=0.049)$. When the subjects with hip osteoarthritis or those with monthly hip pain or hip disability were excluded from the multiple linear regression analysis, the only factor that was associated with hip rotation 
among those with "healthy hip joints" was BMI, explaining about $21 \%$ of its variation.

\section{Discussion}

There were no differences in the passive ROM of the hip between the four groups of athletes with divergent long term patterns of loading. In accordance with previous studies, ${ }^{25}{ }^{26}$ on average no difference was found in the ROM between the right and left hip, although some subjects with severe hip osteoarthritis showed clear right-left rotation differences. In multiple linear regression models, lifetime physical activity or years spent in heavy work was not associated with hip rotation ROM.

Compared with non-ballet dancing controls, a lower range of passive hip adduction and inward rotation among female classical ballet dancers has been reported. ${ }^{9}$ This unbalanced flexibility was attributed to warm up exercises and dancing activities, and the imbalance was worse among older and more experienced dancers. Sarna et $a l^{18}$ found that more than $60 \%$ of our former male elite athletes had engaged in leisure time physical activity or competitive sports throughout their entire adult life, but their hip extension, flexion, and rotation $\mathrm{ROM}$ were similar.

Because the distributions of the variables of lifetime hours spent in different types of athletic activity (table 1) used in regression analysis were somewhat skewed, we also distributed these variables in quartiles and performed the analysis again. The main result of the analysis was similar. However, on reanalysis of the association between hip rotation and different covariates among those without hip osteoarthritis, pain, or disability, soccer playing showed a small explanation rate $(5 \%)$ in addition to BMI $(22 \%)$.

High BMI was associated with low hip rotation in all those who had MRI and in the subgroup without hip osteoarthritis, pain, or disability. There was an association between high BMI and weight lifting. Heavy weight training strengthens muscles and ligaments and may lead to restricted motion of hip joints. However, hip rotation ROM values for weight lifters were similar to those for the other athlete groups, and the association between hip rotation ROM and BMI remains unclear.

Hip osteoarthritis is usually classified radiographically, and symptoms are related to the findings. ${ }^{27}$ On the other hand, some patients with radiological diagnosis of hip osteoarthritis are asymptomatic. In our study it was not possible to make comparisons between subjects with different grades of hip osteoarthritis because of the limited number of osteoarthritic subjects. MRI is at present probably the best method for detecting hip osteoarthritis. However, the possibility remains that even this method may have missed mild hip osteoarthritis, and consequently failed to show a true association between hip osteoarthritis and ROM.

We found that athletes with hip osteoarthritis tend to report monthly hip pain and disability more often than those without this finding. However, $75 \%$ of the athletes with hip osteoarthritis reported no hip pain, and also disability was rare. One explanation for the low rate of symptoms among athletes with hip osteoarthritis diagnosed by MRI may be that our subjects were volunteers and not patients with hip osteoarthritis. Also in $x$ ray studies, subjects with mild osteoarthritic changes are often asymptomatic. On the other hand, reported hip pain and disability seem to have harmful effects on the hip rotation ROM, and symptomatic arthritis is known to predict future disability. ${ }^{28}$

\section{CONCLUSIONS}

Long term loading seems to have no association with passive hip rotation ROM. Subjects with high BMI have lower hip rotation values than those with low BMI. A clear right-left difference in hip rotation appears to be confined to subjects with severe hip osteoarthritis.

This study was financially supported by the Finnish Ministry of Education and Social Insurance Institution, Finland. Contributors: J K designed the study, participated in data collection, and made the statistical analysis of the data as well as wrote the first draft of the manuscript. U K participated in the design and analysis of the study. $H$ R participated in planning the questionnaire and design and collection of the data. $T \mathrm{~V}$ participated in planning the questionnaire and designing the study. S S identified the original study cohort, participated in the design, data collection, and statistical analysis of the data. O I participated in planning the study, was involved in interpreting the results, and edited the paper. S K organised MRI studies and analysed MR images. All investigators read and contributed to successive drafts of the paper, before approving the final version. J $\mathrm{K}$ and $\mathrm{U}$ $\mathrm{K}$ are the guarantors of the paper.

1 Van Saase JLCM, Van Romunde LK, Cats A, et al. Epidemiology of osteoarthritis: the Zoetermeer survey. Comparison of radiological osteoarthritis in a Dutch population with that in 10 other populations. Ann Rheum Dis 1989;48:271-80

2 Hoppenfeld S. Physical examination of the spine and extremities. New York: Appleby-Century-Crofts, 1976.

3 Boone DC, Azen SP. Normal range of motion of joints in male subjects. F Bone foint Surg [Am] 1979;61:756-9.

4 Roach KE, Miles TP. Normal hip and knee active range of motion: the relationship to age. Phys Ther 1991;71: 656-65.

5 American Academy of Orthopedic Surgeons. Foint motion: method of measuring and recording. Chicago: American Academy of Orthopedic Surgeons, 1965.

6 Roaas A, Andersson GBJ. Normal range of motion of the hip, knee and ankle joints in male subjects, 30-40 years of age. Acta Orthop Scand 1982;53:205-8.

7 Pandya S, Florence JM, King WM. Reliability of goniometic measurements in patients with Duchenne muscular dystrophy. Phys Ther 1985;65:1339-42.

8 Croft PR, Nahit ES, Macfarlane GJ, et al. Interobserver reliability in measuring flexion, internal rotation, and external rotation of the hip using plurimeter. Ann Rheum Dis 1996; 55:320-3.

9 Reid DC, Burnham RS, Saboe LA, et al. Lower extremity flexibility patterns in classical ballet dancers and their correlation to lateral hip and knee injuries. Am f Sports Med

Ahlberg Á, Moussa M, Al-Nahdi M. On geographical variations in the normal range of joint motion. Clin Orthop 988;234:229-31

11 Croft PR, Coggon D, Cruddas M, et al. Osteoarthritis of the hip: an occupational disease in farmers. BMF 1992;304: $1269-72$

12 Jacobsson B, Dalén N, Tjörnstrand B. Coxarthrosis and labour. Int Orthop 1987;11:311-13.

13 Vingård E, Alfredsson L, Goldie I, et al. Sports and osteoarthrosis of the hip. Am F Sports Med 1993;21:195-200.

14 Kujala UM, Kaprio J, Sarna S. Osteoarthritis of weight bearing joints of lower limbs in former elite male athletes. BMf 1994;308:231-4.

15 Klünder KB, Rud B, Hansen J. Osteoarthritis of the hip and knee joint in retired football players. Acta Orthop Scand 1980;5:925-7.

16 Lindberg H, Roos H, Gärdsell P. Prevalence of coxarthrosis in former soccer players. Acta Orthop Scand 1993;64:1657.

17 Puranen J, Ala-Ketola L, Peltokallio P, et al. Running and primary osteoarthritis of the hip. BMF 1975;285:424-5.

18 Sarna S, Sahi T, Koskenvuo M, et al. Increased life expectancy of world class male athletes. Med Sci Sports Exerc $1993 ; 25: 237-44$. 
19 Kujala UM, Kettunen J, Paananen H, et al. Knee osteoarthritis in former runners, soccer players, weight 539-46.

20 Räty H, Battié CM, Videman T, et al. Lumbar mobility in former élite male weight-lifters, soccer players, longdistance runners and shooters. Clinical Biomechanics 1997; 12:325-30.

21 Viitanen JV, Kokko M-L, Lehtinen K, et al. Correlation between mobility restrictions and radiological changes in ankylosing spondylitis. Spine 1995;20:492-6.

22 Carter C, Wilkinson J. Persistent joint laxity and congenital dislocation of the hip. $\mathcal{F}$ Bone foint Surg $[\mathrm{Br}]$ 1964;46: $40-5$.

23 Beighton P, Solomon L, Soskolne CL. Articular mobility in an African population. Ann Rheum Dis 1973;32:413-18.
24 Videman T, Sarna S, Battié MC, et al. The long-term effects of physical loading and exercise lifestyles on back-related symptoms, disability, and spinal pathology among men.

25 Bergström G, Bjelle A, Sorensen LB, et al. Prevalence of symptoms and signs of joint impairment at age 79. Scand $\mathcal{F}$ Rehabil Med 1985;17:173-82.

26 Ekstrand J, Wiktorsson M, Öberg B, et al. Lower extremity goniometric measurements: a study to determine their reliability. Arch Phys Med Rehabil 1982;63:171-5.

27 Lawrence JS, Bremner JM, Bier F. Osteo-arthrosis prevalence in the population and relationship between symptoms and x- ray changes. Ann Rheum Dis 1966;25:1-23.

28 Hughes SL, Dunlop D, Edelman P, et al. Impact of joint impairment on longitudinal disability in elderly persons. $\mathcal{F}$ Gerontol 1994;49:S291-300.

\section{Take home message}

We found no association between long term athletic activity and passive hip rotation ROM, but subjects with high BMI had lower ROM than subjects with low BMI. Moreover, only the most severe cases with hip OA had reduced hip rotation.

\section{One doctor's conversion to running}

I started running about three years ago, aged 42 , deliberately to get fitter. Repeated spells of 1-in-1 had precluded hockey, my preferred sport, and I ate for comfort during stressful times.

Easier time off and reliable mobiles made exercise easier to contemplate. Watching my brother in the Highland Cross Biathlon (far harder than a marathon) inspired me to start running, and my wife (the best cook I've ever met, unfortunately) bought me Cannondale bikes. I looked like a pig in Lycra!

My 1998 Highland Cross time was “...geological...”. Quicker this year. I've run three marathons, very slowly. In Los Angeles, a fat runner's vest said "For Mom...and Alice- ....and Faith... and ALL women with breast cancer." Runners overtook him, applauding. I run the New York marathon in November for Imperial Cancer Research with the names of three friends with breast cancer on my own vest. Donations accepted.

Why run? Because I enjoy it, I feel better, I'm slimmer and fitter, it relaxes me, I sleep better, and attractive women are impressed. (My daughters, I mean.) Doctors needn't run marathons to be good at their jobs, but being seen to stay fit, while enjoying themselves is surely an important piece of health education.

LINDSAY EASTON 